\title{
Udayana University International Student Management: A Business Process Reengineering Approach
}

\author{
Cokorda Pramartha ${ }^{1 *}$ and Ni Putu Sri Harta Mimba ${ }^{2}$ \\ 'Department of Computer Science, Udayana University \\ ${ }^{2}$ Accounting Department, Faculty of Economics and Business, Udayana University \\ Jln. Raya Kampus Unud Jimbaran, Bali 80361, Indonesia \\ 'cokorda@unud.ac.id;2p.mimba@unud.ac.id
}

Received: $9^{\text {th }}$ April 2020/ Revised: $6^{\text {th }}$ May 2020/ Accepted: $8^{\text {th }}$ May 2020

\begin{abstract}
How to Cite: Pramartha, C., \& Mimba, N. P. S. H. (2020). Udayana University International Student Management: A Business Process Reengineering Approach. ComTech: Computer, Mathematics and Engineering Applications, 11(2), 57-64. https://doi.org/10.21512/comtech.v11i2.6383
\end{abstract}

\begin{abstract}
The research had two aims. First, it presented an overview and progress in understanding the current business process in the international program of Udayana University, which had a long queue for processing student admission documents. Second, it described how Business Process Reengineering (BPR) helped to improve the educational management services. Multiple interviews and a Forum Group Discussion (FGD) with the stakeholders were conducted. The reviews of the available documents, the current business process, and related complaint records were also carefully performed. The results show that the currently running batch processing system is a major challenge. The proposed solution reengineers the current business process and implements an information technology tool as a driver by digitizing the proposed solutions. The new business process leads to an improvement in processing the international student application from more than 60 days to only 29 days. Moreover, the proposed business process can minimize the opportunity loss of more than Rp3,8 billion annually.
\end{abstract}

Keywords: Udayana University, international student management, Business Process Reengineering (BPR)

\section{INTRODUCTION}

Team-based communication capabilities have become a significant focus for many organizations since the '90s. Many organizations have developed a method that makes coordination among the internal and external members of the team more flexible, with a seamless flow of information (Anders, 2016). Recently, Information Technology (IT) has become a commodity and affordable for any organization. Hence, owning IT as infrastructure no longer gives a competitive advantage to a company (Gunasekaran, Subramanian, \& Papadopoulos, 2017).

As a result, Business Process Reengineering (BPR) is needed because of the increased customer requirements for better services and products. BPR involves fundamentally redesigning and rethinking a business process to achieve dramatic improvements. The improvements can be seen in service, cost, quality, outcomes, innovation, and flexibility, supported by IT (Razalli, Hasnan, \& Noordin, 2017).

The reengineering concept, defined as the fundamental rethinking and radical new design of processes to achieve impressive improvements in contemporary critical measures, such as price, quality, service, and speed, was introduced by Hammer and Champy (Bhaskar, 2018). A business process can be defined as a collection of many interrelated business activities. It can be used to develop a value for a business. Continued improvement of business processes that align with the goals of the business can make the organization or business sustainable (Park, Chung, Khan, \& Park, 2017). Moreover, BPR is a process that requires a radical change of organizational structure, management, process, and organizational culture.

According to Omidi and Khoshtinat (2016), three types of factors affect success in implementing business process reengineering in an organization. First, human factors can be separated into a harmful category (related to the workers' fear of losing their jobs, uncertainty, discomfort, and anxiety in the workplace) and a positive category (collaborative environment, management commitment, and changes in the management system). Second, technical factors include process management (mental models and understanding the work process) and change management (leadership and management style). Last, organizational culture consists of involvement (high involvement in work), integration (staff behavior and stability) and compatibility (continued improvement of the organization over time).

Recent research indicates that the implementation of BPR in public sector organizations has improved their performance and achieved organizational goals. The research also stresses that Information Communication Technology (ICT) is a key driver of applying BPR. It is because IT is affordable and accessible for many organizations (Kasemsap (2020). Another research offers evidence that the implementation of BPR can reduce the 
autonomy of the workforce, provide inferior services to the client, and increase the work extensively for the workers. Moreover, BPR implementation can cut costs and improve efficiency, especially in the case of a government agency that faces budget pressure (Esbenshade, Vidal, Fascilla, \& Ono, 2016).

Udayana University, established in 1962, is the largest and comprehensive university in Bali and Eastern Indonesia. It is a state university under the Indonesian Ministry of Education and Culture. It consists of 13 faculties and 1 postgraduate program. In total, it manages 48 undergraduate study programs, 26 master programs, 12 doctoral programs, 4 vocational programs, 8 professional programs, and 19 specialist doctor programs. Currently, approximately 28.353 domestic students are enrolled in various places in Indonesia. Moreover, it is recognized as the largest university in Indonesia with international student enrollment. The number of international students at Udayana University is currently around 1.500 per year, and they come from varied regions around the world, such as Europe, America, Asia, and Australia. These international students enroll in exchange programs, internship programs, credit transfer programs, and short programs such as summer courses (Universitas Udayana, n.d). Improvements to the current business process are needed to handle the vast increase in the number of international students. It has caused a bottleneck in the international student registration process and led to an increase in the number of complaints in every batch.

In the research, the researchers will discuss the approach to reengineer the business process of Udayana University by using IT. It is to minimize the bottleneck in the international student registration process. The research presents an overview and progress in understanding the current business process in the international program of Udayana University, which had a long queue for processing student admission documents. Then, it also describes how BPR improves educational management services.

\section{METHODS}

The Information System (IS) is usually developed and implemented to improve efficiency and effectiveness. It includes IT resources (hardware, software, and telecommunication networks) and a non-IT resource (data, people, and process or procedure). The IS discipline comprises two categories. First, behavioral science is rooted mainly in natural science research methods and focuses on developing and proving theories. Second, design science emphasizes a problem-solving approach (Venable, PriesHeje, \& Baskerville, 2016). Moreover, design science theory is embedded in the sciences of the artificial domain and engineering domain. In design science, research analysis, design, development, implementation, and evaluation are conducted to solve a problem with an innovative idea. There are six fundamental steps in design science research: 1) identification and accurate description of the IT problem; 2) demonstration that no suitable solutions exist; 3) development and presentation of a new IT artifact to address the issue; 4) evaluation and assessment of the IT artifact; 5) understanding of the value-add of the solutions; and 6) explanation of the implications and benefit of the solution for the organization and community (Venable, Pries-Heje, \& Baskerville, 2017).

It is pointed out that Design Science Research Methodology (DSRM) offers a useful approach to address complex problems, such as those posed by BPR, by creating and evaluating IT artifacts (Peffers, Tuunanen, and Niehaves (2018). The research employs DSRM and follows the approach by Pramartha, Davis, and Kuan (2017). The approach comprises five steps, as shown in Figure 1. For the nature of the research, the DSRM is the most appropriate. Many studies appear to agree that the DSRM process is in sequential order. However, in reality, the research may start from any point, and there is no evidence that researchers should use a sequential order when they conduct their research. If the research comes from an observation of the problem, according to DSRM, the entry point should start from the problem-centered initiation.

The researchers identify the problem and the motivation of the research and begin with a problemcentered approach. First, the researchers notice the increased number of demands from Udayana University's international partners and stakeholders over time. Moreover, the repetitive nature of complaints to Udayana University management indicates that the current business process of international student management needs improvements to meet the demand. The five steps of DSRM related to the research are as follows. The first step is problem identification and motivation. At this point, an observation is conducted by researchers to understand and specify the research problem. Moreover, this point is an essential stage for the researchers to understand the nature of the problem to pursue the best option for a solution.

The second step is to identify the objective of the proposed solutions. This stage summarizes the possible solutions to the problem described in the previous stage. The new proposed IT artifact is described. It also shows how it can support a solution to the problem. Before identifying a solution for the problem defined, researchers perform several in-depth interviews with the Udayana international program coordinators, administration staff, international

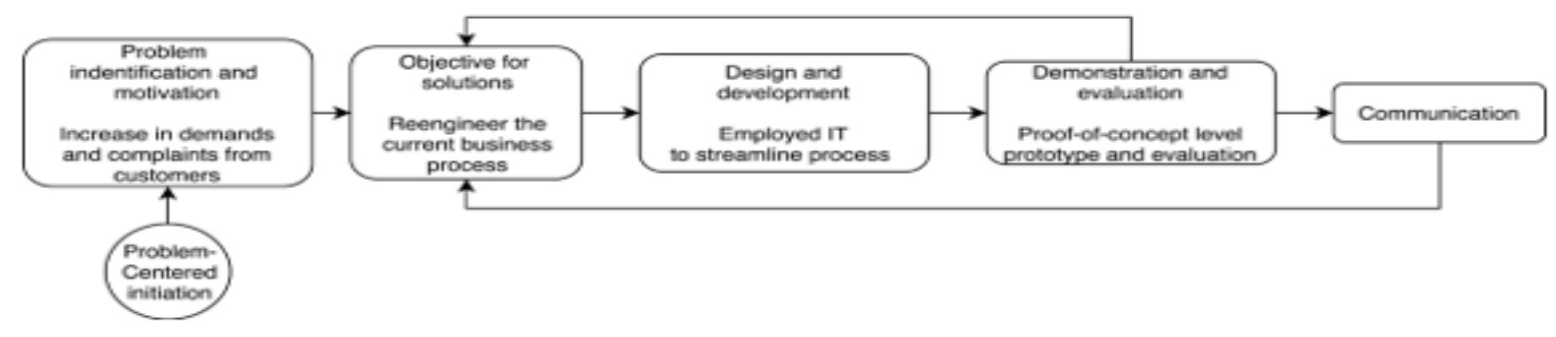

Figure 1 DSRM Approach to Reengineering the Current Business Process 
partners, and Udayana top-level management.

The third step is design and development. This phase aims to model, design, construct, and describe the system development that will be utilized to develop the IT artifact. The contribution of the research is mainly attached to the design of the IT artifact. The design and development process includes determining the functionality and architecture of the IT artifact. It is followed by the development of a proof-of-concept level prototype before the actual artifact is implemented. The proposed solutions employ a prototyping software method to present a vital aspect of the final product with full functionality.

The fourth step is the demonstration of relevant parties and evaluation. Those are necessary factors. Simulation, experimentation, or a proof-of-concept level prototype are used to receive feedback from the user by demonstrating the IT artifact to the relevant users.

The last step is communication. The research outcome will be published in scientific conference proceedings, academic journals, or other relevant outlets to the study. The outcome in the form of an article can be classified into two domain audiences: management-oriented (the audience needs a straightforward understanding of the research process) and technology-oriented (the audience needs to understand the IT artifact design, development, implementation, and evaluation). This last step enables practitioners and researchers to replicate the study. Moreover, this step also contributes to expanding and developing the knowledge base with a similar research environment or case.

\section{RESULTS AND DISCUSSIONS}

The first step of DSRM is problem identification and motivation. The Center for International Programs (CIP) is a unit at Udayana University that offers world-class facilities, resources, and teaching staff. CIP confers the approved credit points under the European Credits Transfer System (ECTS) standard that can be transferred to universities worldwide. Given its excellent facilities and qualified human resources, CIP can offer various education programs suiting national and international development. Udayana University has run the non-degree program for more than ten years.

To attract students from overseas and minimize the expense of marketing, Udayana University collaborates with external parties (partners). This long-standing collaboration has led to an increase in the number of students over time. The international educational programs offered by Udayana University consist of seven bespoke programs that attract many overseas students to study in Bali. The programs are Indonesian language for Foreign Speakers (BIPA), Bali International Programs of Asian Studies (BIPAS), International Business Studies Network (IBSN) (focusing on business management), Udayana International Study Programs (UISP) (short course programs in the fields of personal training and physiotherapy, and social anthropology), GoBali Study Program (focusing on tourism in global marketing, logistics, entrepreneurship, and leadership), UPSkill Program (studying about tropical biology and marine conservation, and sustainability and eco-tourism), Tropical Engineering (offering courses in engineering, South East Asia architecture, and sport and physiotherapy).

In general, most of the Udayana international programs are one-semester programs. It can be taken as a study abroad program for those who are still studying at the undergraduate level. Masters students can also choose some of the courses offered by the IBSN and BIPAS programs. Each module contains credits that are transferable to the ECTS. However, many of the students, especially those enrolled in the BIPA program, are international students with no age limitation. They want to study and experience the new and exciting local culture of Bali. Hence, in general, there is no specific requirement applied.

As previously mentioned, the Udayana University enrolls around 1.500 international students yearly for the seven non-degree international programs. The number of students enrolled has increased over time. Consequently, requests related to the processing of student applications, including the Letter of Acceptance (LoA), study permit, student visa, and the required Izin Tinggal Terbatas (ITAS - semi-permanent stay permit) have also increased dramatically. Udayana University processes the LoA. Meanwhile, study permits are done by the Indonesian Ministry of Research, Technology, and Higher Education. Then, Directorate General of Immigration processes student visas and ITAS.

Currently, Udayana University does not have an integrated system or systematic mechanism to process all of these requests. All requests are processed in a batch system that makes every student application wait in a long queue. The current Udayana University LoA process, which takes around 30 working days, is illustrated in Figure 2.

There are three steps. First, university partners populate a spreadsheet with all required data and email it with support attachments to the Udayana University international program coordinator or CIP. Second, the international program coordinator will check the submitted data. Often, the submitted application is incomplete and must be excluded from the batch until completed.

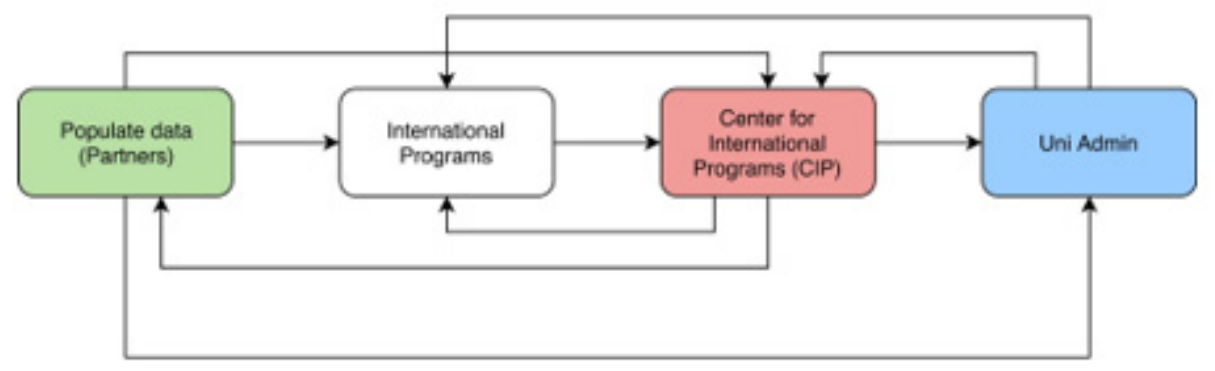

Figure 2 Letter of Acceptance in the Current Business Process (Batch System) 
Last, when all applications are complete, the CIP will write a recommendation for each batch to the university administration to process and issue the LoA. The Rector or Vice-Rector signs the LoA. This process is also done in batches. The university administration will request the signature from the Rector or Vice-Rector whenever all applications are completed.

Aside from the increased number of students registered to the programs, the different time zones of prospective students are another challenge in the communication between Udayana University and the international partner or student regarding their application. This challenge is particularly difficult for students from European countries, where the time zone difference is around 10 hours. The lack of integrated information systems to record all of the student applications makes it challenging for all parties (student, international program partner, international program coordinator, CIP, and Udayana University administration) to track the status of the application. Missing and invalid data are also common with the current system.

Bottlenecks also appear in the student visa application process as the current system owned by the Indonesian Directorate General of Immigration can only handle 500 applications per day for all applicants coming from around Indonesia. Furthermore, in this current system, the maximum number of student visas processed by each University in Indonesia is 5 applications per day.

The second step of DSRM is objective for solutions. As previously mentioned, researchers perform several indepth interviews with the Udayana international program coordinators, administration staff, university international partners, and Udayana top-level management. Moreover, the available historical documents are examined to give a better view of the current process. These documents include emails between students, university international partners, CIP, and university administration; historical application records of a student visa; historical application records from the international partners; and historical records of the procedure to process the university international partner applications.

After carefully studied and examined the process, the researchers propose the BPR approach with the five critical success factors: 1) egalitarian leadership, 2) collaborative working environment, 3) top management commitment, 4) supportive management, and 5) usage of information technology. The digital business process system is a key driver. The challenge of the research is to develop a new business process that can improve the latency of each subprocess in the system. The proposed system also requires top-level management to issue new regulations in the organization, such as implementing a paperless system through digital signatures, a new educational method, and financial fee payment.

The proposed business process in Figure 3 is drawn from the in-depth interviews with related parties (the Udayana international program coordinators, administration staff, university international partners, and Udayana toplevel management). The researchers assess each process and consult with the related parties. The new business process will take 29 days to finish each student application, whereas the current business process took more than 60 days.

The business process can be divided into two primary processes. First, it is internal organization. The process of the international organization includes Udayana international program coordinator or staff, CIP management or staff, and Udayana administration staff. The tasks of the actors in the internal organization block of the process are verifying administration data, admission fee, and a tuition fee for the Udayana international student candidate;

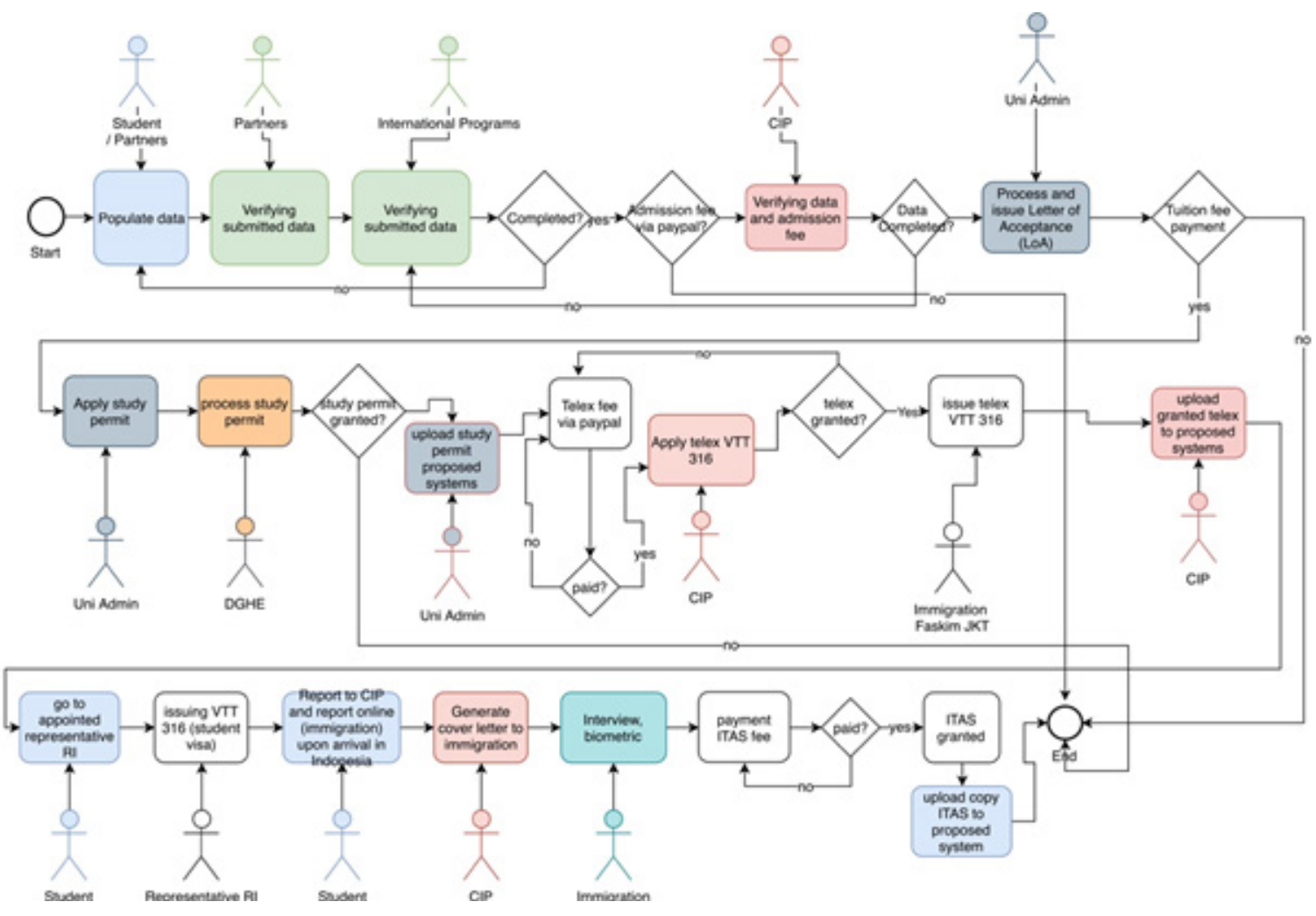

Figure 3 The Proposed New Business Process 
providing an LoA; applying for a student study permit to Indonesian Directorate General of Higher Education (DGHE); applying for an international student visa to Indonesian Indonesian Directorate General of Immigration; and applying for a semi-permanent stay permit once the student arrives in Indonesia for studying.

Second, there is external organization. This external organization is out of the researchers' control. The researchers cannot increase the speed of each subprocess. This process includes Telex VVT application and issue of student visa by an Indonesian representative, such as Embassy of The Republic of Indonesia and Consulate General of the Republic of Indonesia.

Next, part of the proposed solution through BPR is the implementation of digital signatures. A digital signature is a mathematical scheme for verifying the authenticity of digital messages or documents. A valid digital signature, in which the prerequisites are satisfied, gives a recipient solid reason to believe that the message is created by a known sender (authentication). The message is not altered in transit (integrity). The digital signature implements a public key infrastructure, which provides a very high-security level, making it difficult to duplicate. Furthermore, digital signatures have several other advantages: time savings, cost savings, workflow efficiency, security, legal validity, environmental benefit, and business efficiency.

The digital signature is used in the proposed system when the university needs to issue an official document, such as LoA, academic transcript, and academic certificate. Applying this digital signature to the system will speed up the process of giving those documents. It also enables documents to be sent digitally to students who have left the country after the academic program. Moreover, assigning the digital signatures makes the paperwork far more efficient, and many countries accept this as a legal document.

Then, the payments of the new education registration fee and tuition fee are another challenge for the proposed system. Because Udayana University is a state university with Badan Layanan Umum (BLU - Public Service Agency) category, every financial transaction needs to go directly to the Udayana bank account. Furthermore, the payment flow change needs to receive approval from the Indonesian Directorate of Higher Education. In the current process, all financial payments go to the Udayana bank account, and overseas transactions charge USD20 for transaction fee no matter how big the transaction is. To register as a student at Udayana University by national regulation, each candidate pays USD50 for the registration fee and USD1.000 for each program per semester. As a result, most educational partners will delay and pay the registration fees to Udayana in batches to minimize international transaction fees. Thus, the registration fee payment in batches can cause a bottleneck in processing student documents in the batch. In the proposed system (see Figure 4), the researchers suggest involving a third party for financial payments, such as PayPal, to mitigate this issue.

The third step of DSRM is design and development. The prototype appearance and fidelity level are essential to be accepted by potential users. The classification of prototype fidelity can be divided into low, medium, and high. The research focuses on developing medium-fidelity prototyping tools in the form of mobile apps and web-based applications. The medium-fidelity prototyping focuses on presenting detailed information about the layout of content, functionality, and navigation while minimizing the programming activity. Moreover, at this level, a detailed design supports direct manipulation and ease of system production (Alshakhouri, Buchan, \& MacDonell, 2018).

At the early stages of the mobile apps and web-based application development, a medium-fidelity prototype through a mock-up of a Graphical User Interface (GUI) is developed and used to provide a draft requirement functionality of the IT artifact to the researchers and developer. The researchers choose JustInMind prototyping tools for web and mobile apps to realize the early IT artifact and translate the ideas onto the screen quickly. This tool also enables the researchers to develop interactive content with a high-quality page layout.

Furthermore, to progressively develop the interface, the researchers adopt a top-down approach. Utilizing the JustInMind prototyping tool simulates and presents the prototype offline (without the Internet connection) or installing the proposed apps to the mobile device and uploading them to the cloud services. Users can try and experience it using a web browser over the Internet.

In the research, two activities (high-level design and medium-fidelity prototyping) are conducted. In high-level design, there are two steps. First, the functionality of the information included in the proposed IT artifact and the hierarchy of the content is prepared. Second, a rough overall design is sketched and defined related to the navigation scheme.

After the high-level design has finished, the researchers continue developing the medium-fidelity prototype with the five steps. First, it is well-defined font size and screen capabilities. The researchers focus on defining the screen size and screen resolution. It governs how the final IT artifact is displayed on a mobile or tablet

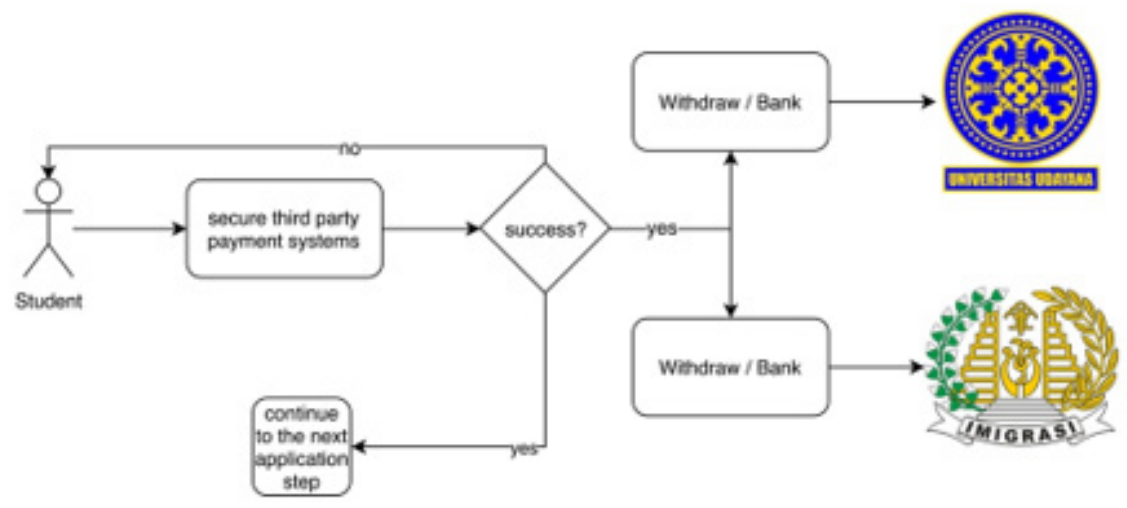

Figure 4 The Proposed Student Payment Solution Flow 
screen and a computer screen, as seen in Figure 5. How many pages will be needed in displaying the content will depend on the chosen font size and how much information should be displayed on the screen. Second, the researchers define and design the main areas, navigation, and homepage schematically. A basic behavior and element layout of the page is defined at this stage (see Figure 6). It comprises the page title, main area, location of the menu, and others.

Third, the researchers insert pages and link them. This stage aims to enable the user to navigate between the pages on the prototype by hyperlinking every page created.
Fourth, the researchers test links and navigation. Informal testing on the navigation of each hyperlink with a typical path becomes the focus of this stage. An offline simulation is prepared to enable users to test navigation and each link on a computer without the Internet connection. Moreover, on the available computer, all pages of the prototype are loaded. Last, the researchers refine the interaction and the page contents whenever the navigation framework and design in the previous steps are finalized. The researchers demonstrate the IT artifact once the iteration process, and all steps are accomplished.

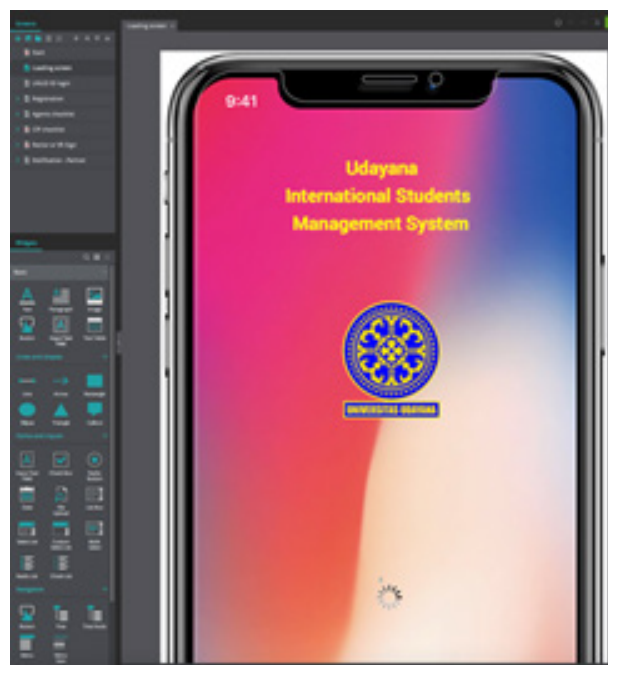

Figure 5 Screen Capabilities and Font Size

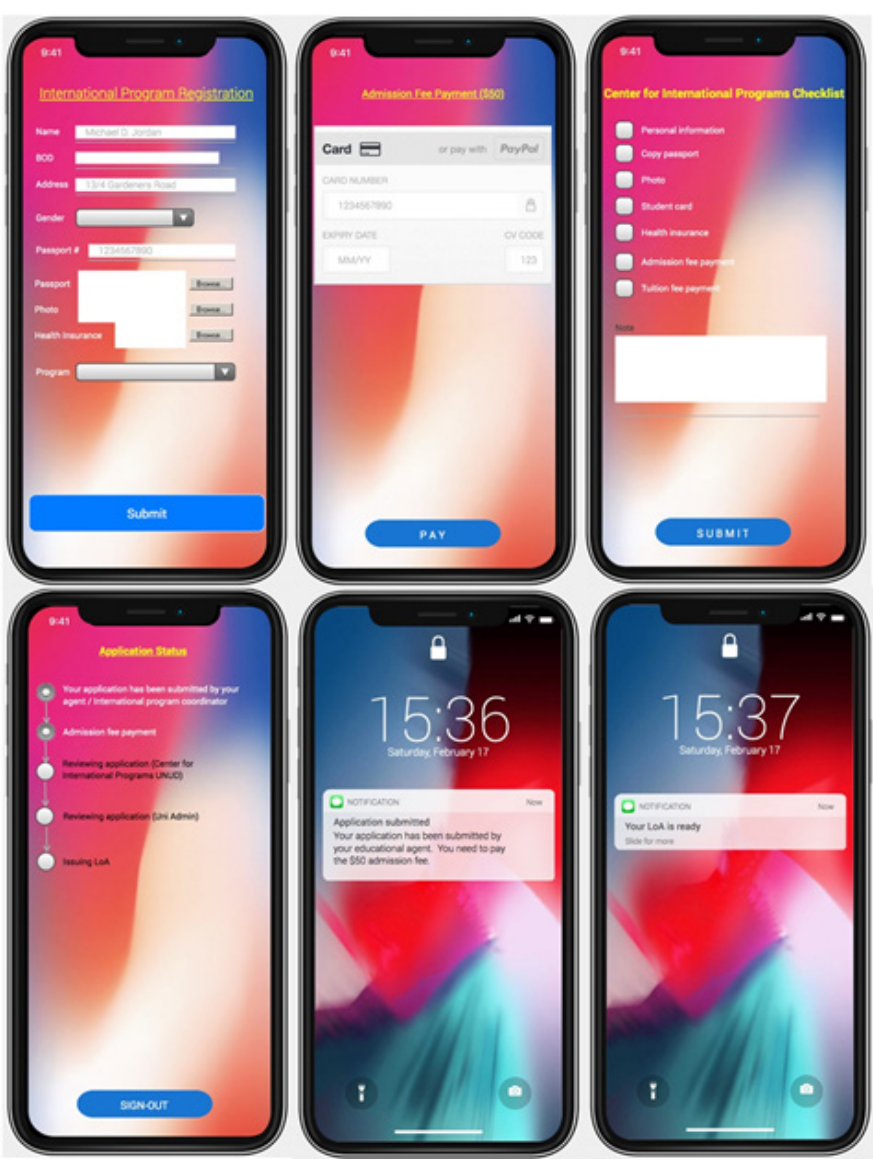

Figure 6 The Example of Simulating 
The fourth step of DSRM is demonstration and evaluation. The proof-of-concept level prototype for the mobile application is demonstrated to the international programs coordinator, educational partners, CIP management, and the Udayana University top-level management. The demonstration is conducted in stages. First, the researchers demonstrate it among the researchers. Second, the researchers invite the international programs coordinator and CIP management, and discuss the proposed solution by demonstrating the proof-of-concept level prototype for the mobile application. Third, the researchers show the educational partners, which are mainly overseas partners, to discuss the prototype and how to integrate it into their system. Finally, after every party agrees to the proposed solution, the researchers demonstrate it to the Udayana top-level management. The last step is the most crucial part because the proposed solutions require changing the current business process in approval from the Udayana management.

Through the demonstration to the relevant parties, the evaluation of the IT artifact is conducted. This demonstration includes assessing the accuracy, completeness, functionality, and other significant artifact features related to the actual problem. When the researchers demonstrate the proposed solution, the researchers also calculated the number of days on the BPR. The process can be divided into two main internal organization areas (the process that Udayana can control) and an external organization, as shown in Figure 7. In the new business process through BPR, the total length in days up until the student can start their semester is 29 days. Meanwhile, the current business process takes more than 60 days. This total of days can be broken down into 8 days for the internal Udayana organization and 21 days for the external organization. Moreover, the proposed solution shows that the new business process can decrease the time to issue of LoA from 30 days to only 4 days. During the demonstration and evaluation stage, the researchers discuss the Udayana opportunity loss by keeping the current business process. This opportunity loss includes admission fee cancelation $(5 \% \times 1.500$ students $\times$ USD50 $($ admin fee) $\times$ Rp14.000 = Rp52,5 million/year) and enrollment cancelation due to long process $(17 \% \times 1.500$ students $\times$
USD1.050 $\times$ Rp14.000 $=$ Rp3,75 billion/year). Finally, all parties agree with the proposed solutions, and the researchers bring the design to the Udayana ICT department to produce the actual IT artifact.

The result indicates that implementing the BPR to international student management system in Udayana University changes the current business process. It provides a better speed in term of services to the stakeholder and decrease the monetary opportunity loss. The results are in line with the research of Esbenshade et al. (2016)

\section{CONCLUSIONS}

The researchers present the details of the research dealing with Udayana University student management through BPR approach. The current business process does all requests in a batch system that makes every student application wait in a long queue, leading to a significant opportunity loss. The proposed solution streams all requests so that it can be processed immediately. The digitization of process, digital signature adoption, and involvement of the third party as financial payment solutions are the critical point of BPR. The contribution includes the design, development, and evaluation of the IT artifact. In designing the IT artifact, a consultation and several in-depth interviews are conducted with relevant parties (Udayana international programs coordinator, CIP, educational partners, and Udayana top-level management). In the form of mobile apps and a web-based level proof-of-concept, the IT artifact has been demonstrated and received feedback for improvement. The new business process improves the international student application from 60 days to only 29 days. Moreover, the proposed business process can minimize the Udayana opportunity loss of more than Rp3,8 billion annually. Currently, the proposed prototype system is in the process of developing at the Udayana ICT department and is expected to be implemented throughout the organization.

The research has some limitations. Some of the areas of the business process is not fully controlled by the Udayana University (Indonesian DGHE and immigration). Also, the system requirement should be changed because of the of ministry restructuring from the Ministry of Research,

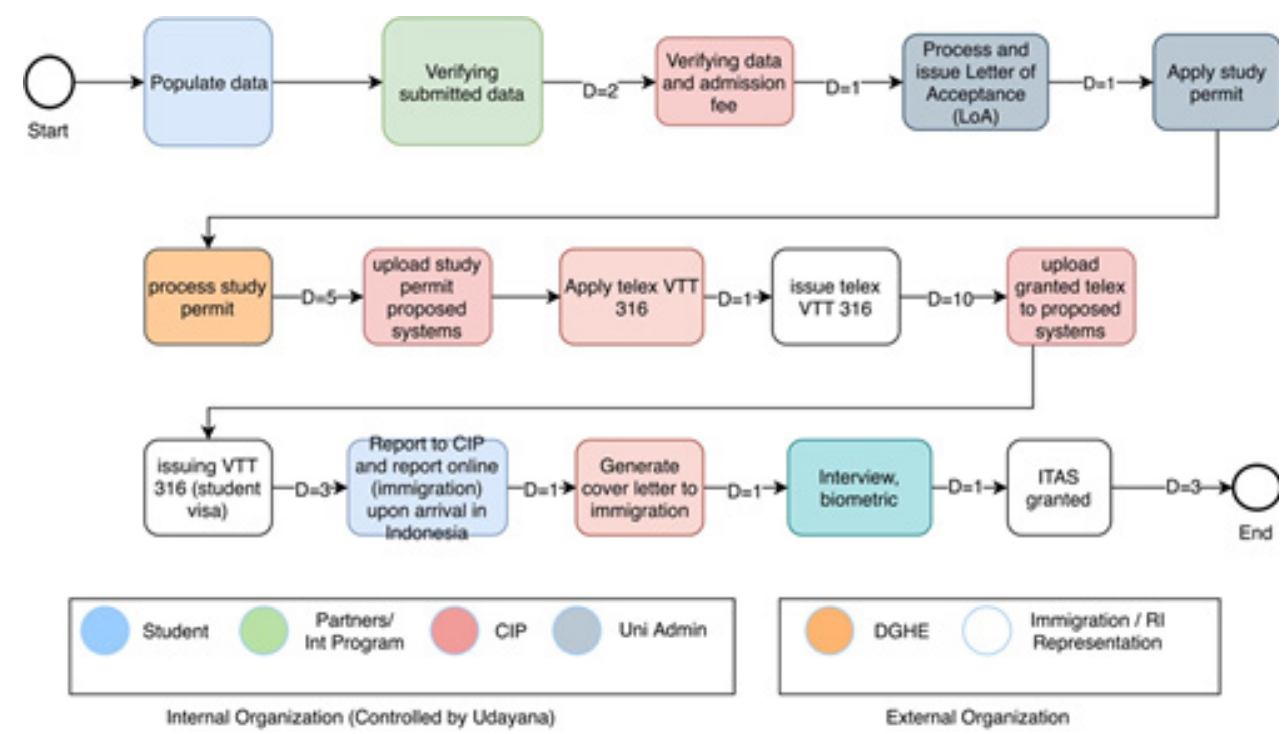

Figure 7 The New Business Process in Days 
Technology and Higher Education to the Ministry of Education. Hence, it will change the proposed business process.

For future research, it is recommended to develop a system with the ability to expedite the process between the university domain (internal process) with Indonesian DGHE, immigration, and Indonesian representation. By this integrated system, all process will be easier to monitor, decrease the process bottleneck, and provide a better service to the end client (students and International partners).

\section{REFERENCES}

Alshakhouri, M., Buchan, J., \& MacDonell, S. G. (2018). Synchronised visualisation of software process and product artefacts: Concept, design and prototype implementation. Information and Software Technology, 98(June), 131-145.

Anders, A. (2016). Team communication platforms and emergent social collaboration practices. International Journal of Business Communication, 53(2), 224-261.

Bhaskar, H. L. (2018). Business process reengineering framework and methodology: A critical study. International Journal of Services and Operations Management, 29(4), 527-556.

Esbenshade, J., Vidal, M., Fascilla, G., \& Ono, M. (2016). Customer-driven management models for choiceless clientele? Business process reengineering in a California welfare agency. Work, Employment and Society, 30(1), 77-96.

Gunasekaran, A., Subramanian, N., \& Papadopoulos, T. (2017). Information technology for competitive advantage within logistics and supply chains: A review. Transportation Research Part E: Logistics and Transportation Review, 99(March), 14-33.

Kasemsap, K. (2020). The roles of business process modeling and business process reengineering in e-government. In Open Government: Concepts,
Methodologies, Tools, and Applications (pp. 22362267). IGI Global.

Omidi, A., \& Khoshtinat, B. (2016). Factors affecting the implementation of business process reengineering: Taking into account the moderating role of organizational culture (Case study: Iran Air). Procedia Economics and Finance, 36(16), 425-432.

Park, G., Chung, L., Khan, L., \& Park, S. (2017). A modeling framework for business process reengineering using big data analytics and a goal-orientation. In $201711^{\text {th }}$ International Conference on Research Challenges in Information Science (RCIS) (pp. 21-32). IEEE.

Peffers, K., Tuunanen, T., \& Niehaves, B. (2018). Design science research genres: Introduction to the special issue on exemplars and criteria for applicable design science research. European Journal of Information Systems, 27(2), 129-139.

Pramartha, C., Davis, J. G., \& Kuan, K. K. Y. (2017). Digital preservation of cultural heritage: An ontology-based approach. In The 28 $8^{\text {th }}$ Australasian Conference on Information Systems (pp. 1-12).

Razalli, M. R., Hasnan, N., \& Noordin, A. (2017). Business process reengineering and quality performance in the Islamic banks: The information technology as a moderator. International Journal of Supply Chain Management, 6(3), 300-308.

Universitas Udayana. (n.d). Universitas Udayana. Retrieved from https://www.unud.ac.id/

Venable, J., Pries-Heje, J., \& Baskerville, R. (2016). FEDS: A framework for evaluation in design science research. European Journal of Information Systems, 25(1), 77-89.

Venable, J. R., Pries-Heje, J., \& Baskerville, R. (2017). Choosing a Design Science Research Methodology. In $28^{\text {th }}$ Australasian Conference on Information Systems IEEE/ ACIS International Conference on Computer and Information Science. 